\title{
PENGARUH PERBANDINGAN SEMOLINA DAN TEPUNG BERAS HITAM TERHADAP KARAKTERISTIK PASTA FETTUCINE BASAH
}

The Effect Ratio of Semolina And Black Rice Flour to The Characteristics of Wet Fettucine Paste

\author{
Ni Kadek Nova Wulandari ${ }^{1)}$, I Gusti Ayu Ekawati ${ }^{2}$, I Nengah Kencana Putra ${ }^{2)}$ \\ ${ }^{1)}$ Mahasiswa Program Studi Imu dan Teknologi Pangan, Fakultas Teknologi Pertanian, Unud \\ ${ }^{2)}$ Dosen Program Studi Imu dan Teknologi Pangan, Fakultas Teknologi Pertanian, Unud \\ Kampus Bukit Jimbaran, Badung-Bali
}

\section{ABSTRACT}

\begin{abstract}
This study aims to determine the effect ratio of semolina and black rice flour to the characteristics of wet fettucine paste and to know the right ratio for semolina and black rice flour to produce wet fettucine paste with the best characteristics. This study used a Completely Randomized Design (RAL) with a comparison treatment of semolina and black rice flour : 100\%: $0 \%$; $90 \%: 10 \%$; $80 \%: 20 \% ; 70 \%: 30 \% ; 60 \%: 40 \%$; and $50 \%: 50 \%$. The treatment was repeated 3 times to obtain 18 units of the experiment. The data obtained were analyzed by variance and if there was influence between treatments followed by Duncan test. The results showed that the use of semolina and black rice flour had significant effect on water content, ash content, antioxidant capacity, total anthocyanin, flavor, taste, texture, and overall acceptance of wet fettucine pasta. Ratio of $50 \%$ semolina and $50 \%$ black rice flour had the best characteristics with $56,49 \%$ water content, $0.69 \%$ ash content, $2.26 \mathrm{mg} / 100 \mathrm{~g}$ total anthocyanin, $23.02 \%$ antioxidant capacity, color purplish black and ordinary, texture rather supple and rather liked, flavor rather liked, taste rather liked and overall acceptance ordinary.
\end{abstract}

Keywords: pasta, fettucine, black rice, semolina

\section{PENDAHULUAN}

Pasta merupakan jenis bahan pangan hasil produk ekstruksi yang terbuat dari campuran semolina, minyak, air, garam, dan telur. Awal mulanya pasta terkenal di Italia kemudian menyebar ke Amerika dan Eropa. Pasta saat ini sudah menjadi makanan yang dikenal di seluruh dunia (Gisslen, 2011). Produk pasta umumnya dibuat dari semolina berasal dari gandum durum yang dihaluskan (Gisslen, 2013). Semolina mengandung gluten yang berperan dalam menentukan kekenyalan terhadap adonan makanan sehingga semolina sangat cocok untuk membuat makanan seperti roti, mi, pasta, dan lain-lain. Berdasarkan jenisnya pasta dibedakan menjadi pasta basah dan pasta kering. Pasta basah saat ini sudah banyak dijual dalam bentuk frozen salah satu contoh pasta basah yaitu fettucine (Anon., 2006).

Jenis pasta ada yang berwarna merah yang dibuat dari campuran bit, warna hijau dari campuran bayam dan warna hitam dari tinta cumi. Pasta hitam dari tinta cumi umumnya merupakan produk impor dan tidak semua orang dapat mengkonsumsinya karena tidak semua orang suka aroma dari tinta cumi. Hasil penelitian dari Putri dan Novita, (2013) terhadap uji kesukaan, menunjukkan bahwa aroma pasta fettucine dengan perbandingan tinta cumi belum begitu diterima. Pewarna yang dapat digunakan sebagai pengganti warna hitam dalam pembuatan pasta salah

*Korespondensi Penulis:

Email: vawulan@gmail.com ${ }^{1)}$ 
satunya adalah beras hitam.

Beras hitam merupakan salah satu jenis varietas beras berwarna ungu pekat yang banyak terdapat di Jatiluwih, Tabanan. Beras hitam juga dikenal sebagai salah satu pangan fungsional karena dapat meningkatkan daya tahan tubuh, memperbaiki kerusakan sel hati, mencegah gangguan fungsi ginjal, mencegah kanker atau tumor, memperlambat penuaan, sebagai antioksidan, membersihkan kolestrol dalam darah, dan mencegah anemia (Suardi dan Ridwan, 2009).

Oki et al. (2001) dalam Narwidina (2009) mengatakan bahwa beras hitam (Oryza sativa L. indica) memiliki perikarp, aleuron, dan endosperm yang berwarna merah-biru-ungu pekat yang menunjukkan adanya kandungan antosianin. Beras hitam mengandung 351 kkal dan kandungan antioksidan sebesar 46,20\% dalam 100 gram bahan (Mangiri et al., 2015).

Berdasarkan hal tersebut di atas, maka tepung beras hitam digunakan dalam pembuatan pasta fettuccine karena memiliki keunggulan yaitu kandungan antioksidannya yang tinggi dan sebagai pewarna alami. Oleh karena itu, perlu dilakukan penelitian untuk mengetahui pengaruh perbandingan tepung beras hitam terhadap kerakteristik pasta fettucine basah.

\section{METODE PENELITIAN}

\section{Tempat dan Waktu}

Penelitian ini dilaksanakan di Laboratorium Pengolahan Pangan, Laboratorium Biokimia dan Nutrisi, Laboratorium Analisis Pangan, serta Laboratorium Rekayasa Proses dan Pengendalian Mutu Fakultas Teknologi Pertanian, Universitas Udayana. Penelitian ini dilaksanakan dari bulan September sampai Desember 2017.

\section{Bahan dan Alat}

Bahan- bahan yang digunakan dalam pelaksanaan penelitian ini terdiri dari bahan baku, bahan tambahan, dan bahan kimia. Bahan baku yang digunakan terdiri dari beras hitam dan semolina yang diperoleh dari toko UD. Fenny, Denpasar. Bahan tambahan terdiri dari garam, telur, minyak merk bimoli dan air mineral merk aqua yang diperoleh di swalayan Tiara Dewata. Bahan kimia yang digunakan dalam melakukan analisis meliputi $\mathrm{HCl}$, aquades, asam galat, $\mathrm{KCl}$, asam sitrat, natrium sitrat, methanol, 2,2-diphenyl-1-picrylhydrazyl (DPPH), dan etanol.

Alat- alat yang digunakan dalam proses pembuatan pasta fettucine yaitu loyang, sendok, ayakan tepung 80 mesh, oven (sense), timbangan digital (ACIS), waskom, pasta maker, kompor gas (Rinnai), dan alat pengukus. Peralatan yang digunakan untuk analisis sifat fisik dan kimia antara lain desikator, oven (Memmert), timbangan analitik (Shimadzu), aluminium foil, labu erlenmeyer (Pyrex), pipet volume (Pyrex), labu takar (Pyrex), vortex (Maxi Mix II Type 367000), mikropipet (Socorex), spektrofotometer (Thermo Scientific Genesis 10S UV-Vis), cawan botol timbang, pinset, spatula, destruktor muffle purnance (Daihan), pipet tetes, gelas beaker (Pyrex), gelas ukur (Pyrex), pompa karet, tabung reaksi (Pyrex), dan lembar kuisioner untuk uji sensoris.

\section{Pelaksanaan Penelitian}

Persiapan bahan-bahan yang digunakan dalam pembuatan pasta fettucine yaitu tepung beras hitam, semolina, air, garam, telur, dan minyak. Bahan yang digunakan kemudian ditimbang sesuai dengan formulasi pada Tabel 1.

\section{Pembuatan Tepung Beras Hitam}

Bahan baku yang digunakan adalah $1 \mathrm{~kg}$ beras hitam yang bersih. Beras yang sudah dicuci bersih dimasukkan ke dalam baskom yang berisi air sebanyak 1 liter kemudian direndam selama \pm 15 menit. Setelah proses perendaman kemudian beras diangkat dan ditiriskan. Proses penepungan beras hitam 
menggunakan mesin penepung kemudian dikeringkan dengan sinar matahari selama 15 menit, setelah itu diayak dengan menggunakan ayakan 80 mesh.

Persiapan dan penimbangan bahan sesuai perlakuan dilakukan sebelum proses pembuatan pasta fettucine. Semolina, tepung beras hitam, telur, garam, air, dan minyak dicampur, setelah semua bahan tercampur rata dan terbentuk adonan kemudian adonan dibentuk bulat dan didiamkan selama 1 jam. Adonan yang sudah didiamkan digiling hingga tipis lalu dibentuk menggunakan Pasta Maker.

Adonan pasta fettuccine dimasukkan ke dalam air mendidih selama 5-7 menit atau ditandai dengan mengapungnya pasta fettucine ke permukaan air, setelah itu, pasta fettuccine yang sudah matang diangkat dan ditiriskan.

Tabel 1. Formula Pasta Fettucine

\begin{tabular}{|c|c|c|c|c|c|c|c|}
\hline \multirow[t]{2}{*}{ No. } & \multirow{2}{*}{$\begin{array}{c}\text { Komposisi Bahan } \\
(\%)\end{array}$} & \multicolumn{6}{|c|}{ Perlakuan } \\
\hline & & P0 & P1 & $\mathrm{P} 2$ & P3 & $\mathrm{P} 4$ & P5 \\
\hline 1. & Semolina & 100 & 90 & 80 & 70 & 60 & 50 \\
\hline 2. & Tepung beras hitam & 0 & 10 & 20 & 30 & 40 & 50 \\
\hline 3. & Air & 12 & 12 & 12 & 12 & 12 & 12 \\
\hline 4. & Garam & 1 & 1 & 1 & 1 & 1 & 1 \\
\hline 5. & Telur & 25 & 25 & 25 & 25 & 25 & 25 \\
\hline 6. & Minyak & 3 & 3 & 3 & 3 & 3 & 3 \\
\hline
\end{tabular}

Keterangan : persentase berdasarkan jumlah tepung beras hitam dan semolina(100\%)

\section{Variabel yang Diamati}

Variabel yang diamati dalam penelitian ini adalah analisis kadar air dengan metode pengeringan (Sudarmaji et al., 1997), kadar abu dengan metode pengabuan (Sudarmaji et al, 1997), total antosianin dengan metode $\mathrm{pH}$ differensial (Lee, 2005), kapasitas antioksidan dengan metode DPPH (Yun, 2001), serta sifat sensoris dilakukan terhadap tekstur, warna, rasa, aroma, dan penerimaan keseluruhan menggunakan uji hedonik dan warna dan tekstur menggunakan uji skoring (Soekarto, 1985).

\section{HASIL DAN PEMBAHASAN}

Hasil analisis bahan baku yang meliputi kadar air dan kadar abu semolina dan tepung beras hitam dapat dilihat pada Tabel 2 .

\section{Kadar Air}

Hasil sidik ragam menunjukkan bahwa perlakuan perbandingan semolina dengan tepung beras hitam berpengaruh nyata $(\mathrm{P}<0,05)$ terhadap kadar air pasta fettucine basah. Berdasarkan Tabel 3, menunjukkan bahwa nilai rata-rata kadar air pada pasta fettucine basah dengan berbagai perlakuan berkisar antara 56,49\% sampai dengan $62,32 \%$. Nilai tertinggi pada perlakuan P0 (100\% semolina dan $0 \%$ tepung beras hitam) sebesar $62,32 \%$ dan berbeda tidak nyata dengan P1, P2, dan P3, sedangkan nilai terendah pada perlakuan P5 (50\% semolina dan 50\% tepung beras hitam) yaitu sebesar $56,49 \%$ dan berbeda tidak nyata dengan P2, P3, dan P4.

Penurunan kadar air pasta fettucine basah disebabkan oleh bertambahnya konsentrasi tepung beras hitam, semakin banyak penambahan tepung beras hitam semakin rendah kadar air pasta fettucine basah. Hal ini disebabkan oleh tepung beras hitam yang memiliki kadar air lebih rendah dibandingkan semolina. Berdasarkan hasil analisis bahan baku (Tabel 2), kandungan kadar air tepung beras hitam lebih rendah yaitu sebesar 13,00\% dibandingkan dengan semolina yaitu sebesar $14,52 \%$.

\section{Kadar Abu}

Hasil sidik ragam menunjukkan bahwa 
perlakuan perbandingan semolina dengan tepung beras hitam berpengaruh sangat nyata $(\mathrm{P}<0,01)$ terhadap kadar abu pasta fettucine basah. Berdasarkan Tabel 3, menunjukkan bahwa nilai rata-rata kadar abu pada pasta fettucine basah dengan berbagai perlakuan berkisar antara 0,31\% sampai dengan 0,69\%. Nilai terendah pada P1 $(90 \%$ semolina dan $10 \%$ tepung beras hitam) yaitu sebesar $0,27 \%$ dan berbeda tidak nyata dengan P0 sedangkan tertinggi diperoleh pada P5 (50\% semolina dan $50 \%$ tepung beras hitam) yaitu sebesar $0,69 \%$ dan berbeda tidak nyata dengan P3 dan P4.Hal ini disebabkan oleh tepung beras hitam yang memiliki kadar abu yang lebih tinggi dibandingkan semolina. Berdasarkan hasil analisis bahan baku (Tabel 2), kandungan kadar abu tepung beras hitam lebih tinggi yaitu sebesar $0,55 \%$ dibandingkan dengan semolina yaitu sebesar $0,33 \%$.

Tabel 2. Nilai Hasil Analisis Bahan Baku Kadar Air dan Kadar Abu Semolina dan Tepung Beras Hitam

\begin{tabular}{lll}
\hline Uji & Tepung Beras Hitam (\%) & Semolina (\%) \\
\hline Kadar Air & 13,00 & 14,52 \\
Kadar Abu & 0,55 & 0,33 \\
\hline
\end{tabular}

Tabel 3.Nilai Rata-Rata Kadar Air, Kadar Abu, Total Antosianin, dan Kapasitas Antioksidan, Pasta Fettucine Basah

\begin{tabular}{ccccc}
\hline Perlakuan & Kadar Air (\%) & Kadar Abu(\%) & Total Antosianin (\%) & $\begin{array}{c}\text { Kapasitas Antioksidan } \\
(\%)\end{array}$ \\
\hline P0 & $62,32 \pm 0,56 \mathrm{a}$ & $0,31 \pm 0,06 \mathrm{~cd}$ & $0 \mathrm{~d}$ & $0 \mathrm{~d}$ \\
P1 & $61,55 \pm 0,22 \mathrm{ab}$ & $0,27 \pm 0,19 \mathrm{~d}$ & $1,60 \pm 0,09 \mathrm{c}$ & $15,83 \pm 0,69 \mathrm{c}$ \\
P2 & $60,24 \pm 0,57 \mathrm{abc}$ & $0,47 \pm 0,01 \mathrm{bc}$ & $1,61 \pm 0,16 \mathrm{c}$ & $17,07 \pm 0,59 \mathrm{c}$ \\
P3 & $59,03 \pm 0,20 \mathrm{abc}$ & $0,52 \pm 0,04 \mathrm{ab}$ & $1,89 \pm 0,09 \mathrm{~b}$ & $19,18 \pm 0,46 \mathrm{~b}$ \\
P4 & $58,26 \pm 0,12 \mathrm{bc}$ & $0,57 \pm 0,04 \mathrm{ab}$ & $2,14 \pm 0,05 \mathrm{a}$ & $21,71 \pm 1,27 \mathrm{a}$ \\
P5 & $56,49 \pm 0,66 \mathrm{c}$ & $0,69 \pm 0,16 \mathrm{a}$ & $2,26 \pm 0,11 \mathrm{a}$ & $23,02 \pm 0,49 \mathrm{a}$ \\
\hline
\end{tabular}

Keterangan : Huruf yang sama di belakang nilai rata-rata pada kolom yang sama menunjukkan perbedaan tidak nyata $(\mathrm{P}>0,05)$.

\section{Total Antosianin}

Hasil sidik ragam menunjukkan bahwa perbandingan semolina dengan tepung beras hitam berpengaruh sangat nyata $(\mathrm{P}<0,01)$ terhadap total antosianin pasta fettucine basah. Berdasarkan Tabel 3, menunjukkan nilai ratarata total antosianin pada pasta fettucine basah dengan berbagai perlakuan berkisar antara $1,60 \mathrm{mg} / 100 \mathrm{~g}$ sampai dengan $2,26 \mathrm{mg} / 100 \mathrm{~g}$. Nilai terendah pada P1 (90\% semolina dan 10 $\%$ tepung beras hitam) yaitu sebesar 1,60 $\mathrm{mg} / 100 \mathrm{~g}$ dan berbeda tidak nyata dengan $\mathrm{P} 2$ sedangkan tertinggi diperoleh pada P5 (50\% semolina dan $50 \%$ tepung beras hitam) yaitu sebesar 2,26 mg/100g dan berbeda tidak nyata dengan P4. Semakin banyak penambahan tepung beras hitam maka total antosianin semakin tinggi. Hal ini disebabkan karena tepung beras hitam mempunyai kandungan antosianin sedangkan semolina tidak memiliki kandungan antosianin.

\section{Kapasitas Antioksidan}

Hasil sidik ragam menunjukkan bahwa perlakuan perbandingan semolina dengan tepung beras hitam berpengaruh sangat nyata $(\mathrm{P}<0,01)$ terhadap kapasitas antioksidan pasta fettucine basah. Berdasarkan Tabel 3, menunjukkan nilai rata-rata kapasitas antioksidan pada pasta fettucine basah dengan berbagai perlakuan berkisar antara $15,83 \%$ sampai dengan $23,02 \%$. Nilai terendah pada P1 (90\% semolina dan $10 \%$ tepung beras hitam) yaitu sebesar $15,83 \%$ dan berbeda tidak nyata dengan $\mathrm{P} 2$ sedangkan tertinggi diperoleh pada P5 (50\% semolina dan 50\% tepung beras 
hitam) yaitu sebesar $23,02 \%$ dan berbeda tidak nyata dengan P4. Semakin banyak penambahan tepung beras hitam maka kapasitas antioksidan semakin tinggi. Hal ini disebabkan karena beras hitam mempunyai kandungan antioksidan sebesar 46,20\% (Mangiri et al., 2015) sedangkan semolina tidak mengandung antioksidan. Total antosianin dalam beras hitam berperan sebagai antioksidan dalam menangkal radikal bebas, semakin tinggi jumlah total antosianin maka semakin tinggi kapasitas antioksidan yang terkandung di dalamnya.

\section{Evaluasi Sifat Sensoris}

Hasil sidik ragam nilai rata-rata penilaian sifat sensoris pasta fettucine basah dapat dilihat pada Tabel 4 (uji hedonik untuk warna, aroma,rasa,tekstur, dan penerimaan keseluruhan) dan Tabel 5 (uji skoring untuk warna dan tekstur).

Tabel 4. Nilai rata-rata uji hedonik warna, aroma, rasa, tekstur dan penerimaan keseluruhan pasta fettucine basah.

\begin{tabular}{|c|c|c|c|c|c|}
\hline \multirow{2}{*}{ Perlakuan } & \multicolumn{5}{|c|}{ Nila rata-rata uji hedonik } \\
\hline & Warna & Aroma & Rasa & Tesktur & Penerimaan keseluruh \\
\hline P0 & $3,50 \pm 0,99 a$ & $4,30 \pm 0,70 c$ & $3,50 \pm 0,99 a$ & $4,30 \pm 1,44 b c$ & $4,20 \pm 0,77 \mathrm{ab}$ \\
\hline $\mathrm{P} 1$ & $4,20 \pm 0,77 \mathrm{a}$ & $4,30 \pm 0,72 \mathrm{c}$ & $4,20 \pm 0,77 a$ & $4,40 \pm 0,98 \mathrm{abc}$ & $4,00 \pm 0,65 b$ \\
\hline $\mathrm{P} 2$ & $4,10 \pm 1,03 a$ & $4,60 \pm 0,63 b c$ & $4,10 \pm 1,06 \mathrm{a}$ & $4,20 \pm 1,01 \mathrm{c}$ & $4,30 \pm 0,97 \mathrm{ab}$ \\
\hline P3 & $4,40 \pm 0,91 \mathrm{a}$ & $5,00 \pm 0,75 a b$ & $4,40 \pm 0,91 \mathrm{a}$ & $5,30 \pm 0,97 a$ & $4,70 \pm 0,45 a$ \\
\hline $\mathrm{P} 4$ & $4,20 \pm 0,77 a$ & $5,10 \pm 0,63 a$ & $4,30 \pm 0,70 \mathrm{a}$ & $5,20 \pm 1,56 \mathrm{ab}$ & $3,90 \pm 0,96 b$ \\
\hline P5 & $3,90 \pm 0,79 a$ & $5,30 \pm 0,70 \mathrm{a}$ & $4,00 \pm 0,79 a$ & $4,20 \pm 1,26 \mathrm{c}$ & $3,70 \pm 0,96 b$ \\
\hline
\end{tabular}

Keterangan : Nilai rata - rata yang diikuti oleh huruf yang berbeda pada kolom yang sama menunjukkan berbeda nyata pada Uji Duncan $(\mathrm{P}<0,05)$.

Kriteria hedonik : 1 (sangat tidak suka), 2 (tidak suka), 3 (agak tidak suka), 4 (biasa), 5 (agak suka), 6 (suka), 7 (sangat suka).

Tabel 5. Nilai rata-rata uji skoring warna dan tekstur pasta fettucine basah.

\begin{tabular}{ccc}
\hline Perlakuan & \multicolumn{2}{c}{ Nilai rata - rata uji skoring } \\
& Warna & Tekstur \\
\hline P0 & $1,00 \pm 0,0 \mathrm{~d}$ & $4,60 \pm 0,50 \mathrm{a}$ \\
P1 & $1,20 \pm 0,41 \mathrm{~d}$ & $4,63 \mathrm{a}$ \\
P2 & $2,00 \pm 0,53 \mathrm{c}$ & $4,30 \pm 0,70 \mathrm{a}$ \\
P3 & $3,50 \pm 0,91 \mathrm{~b}$ & $4,50 \pm 0,51 \mathrm{a}$ \\
P4 & $4,50 \pm 0,51 \mathrm{a}$ & $3,50 \pm 0,51 \mathrm{~b}$ \\
P5 & $4,60 \pm 0,50 \mathrm{a}$ & $3,50 \pm 1,12 \mathrm{~b}$ \\
\hline
\end{tabular}

Keterangan : Nilai rata - rata yang diikuti oleh huruf yang berbeda pada kolom yang sama menunjukkan berbeda nyata pada Uji Duncan $(\mathrm{P}<0,05)$.

Kriteria tekstur : 1 (tidak kenyal), 2 (agak tidak kenyal), 3 (agak kenyal), 4 (kenyal), 5 (sangat kenyal).

Kriteria warna : 1 (putih keunguan), 2 (ungu keputihan), 3 (ungu), 4 (ungu kehitaman), 5 (hitam keunguan).

\section{Warna}

Hasil sidik ragam menunjukkan bahwa perlakuan perbandingan semolina dengan tepung beras hitam berpengaruh tidak nyata $(\mathrm{P}>0,05)$ terhadap warna (uji hedonik) pasta fettucine basah. Berdasarkan Tabel 4, menunjukkan bahwa nilai rata-rata uji hedonik terhadap warna pasta fettucine basah dengan berbagai perlakuan berkisar antara 3,50 sampai dengan 4,40 dengan kriteria biasa.

Berdasarkan sidik ragam menunjukkan bahwa perlakuan perbandingan semolina dan tepung beras hitam berpengaruh sangat nyata $(\mathrm{P}<0,01)$ terhadap warna (uji skoring) pasta fettucine basah. Berdasarkan Tabel 5, menunjukkan bahwa nilai rata-rata uji skoring warna pasta fettucine basah dengan berbagai perlakuan berkisar antara 1,00-4,60 dengan 
kriteria warna putih keunguan hingga hitam keunguan. Penerimaan terhadap warna (uji skoring) tertinggi diperoleh pada perlakuan P5 (hitam keunguan) dan berbeda tidak nyata dengan P4 sedangkan terendah diperoleh pada P0 (putih keunguan) dan berbeda tidak nyata dengan P1. Semakin banyak penambahan tepung beras hitam maka warna pasta fettucine basah semakin berwarna hitam keunguan karena beras hitam mengandung antosianin.

\section{Aroma}

Berdasarkan sidik ragam diperoleh hasil bahwa perlakuan perbandingan semolina dengan tepung beras hitam berpengaruh sangat nyata $(\mathrm{P}<0,01)$ terhadap aroma (uji hedonik) pasta fettucine basah. Berdasarkan Tabel 4, hasil sidik ragam menunjukkan bahwa nilai rata-rata uji hedonik terhadap aroma pasta fettucine basah berkisar antara 4,30\% - 5,30\% dengan kriteria biasa hingga agak suka.

Panelis lebih menyukai aroma pasta fettucine basah dengan perlakuan P5 (agak suka) dan berbeda tidak nyata dengan, P3 dan P4 sedangkan terendah pada P0 (biasa) dan berbeda tidak nyata dengan P1 dan P2. Hal ini disebabkan karena semakin tinggi penambahan tepung beras hitam sehingga aroma beras hitam pada pasta fettucine basah semakin kuat.

\section{Rasa}

Berdasarkan sidik ragam diperoleh hasil bahwa perlakuan perbandingan semolina dan tepung beras hitam berpengaruh tidak nyata $(\mathrm{P}>0,05)$ terhadap rasa pasta fettucine basah. Berdasarkan Tabel 4, menunjukkan bahwa nilai rata-rata (uji hedonik) terhadap rasa pasta fettucine basah dengan kriteria biasa.

\section{Tekstur}

Berdasarkan sidik ragam diperoleh hasil bahwa perlakuan perbandingan semolina dengan tepung beras hitam berpengaruh nyata $(\mathrm{P}<0,05)$ terhadap tekstur (uji hedonik) pasta fettucine basah. Berdasarkan Tabel 4, penerimaan terhadap tekstur (uji hedonik) tertinggi diperoleh pada perlakuan P3 (agak suka) dan berbeda tidak nyata dengan P1 dan P4, sedangkan terendah diperoleh pada perlakuan P2 (biasa) dan berbeda tidak nyata dengan P0 dan P5.

Berdasarkan sidik ragam diperoleh hasil bahwa perlakuan perbandingan semolina dengan tepung beras hitam berpengaruh nyata $(\mathrm{P}<0,05)$ terhadap tekstur (uji skoring) pasta fettucine basah. Berdasarkan Tabel 5, uji skoring terhadap tekstur pasta fettucine basah dengan berbagai perlakuan berkisar antara 3,50 - 4,60 dengan kriteria tekstur agak kenyal hingga sangat kenyal. Penerimaan terhadap tekstur (uji skoring) tertinggi diperoleh pada perlakuan P0 (sangat kenyal) dan berbeda tidak nyata dengan P1, P2 dan P3, sedangkan terendah diperoleh pada perlakuan P5 (agak kenyal) dan berbeda tidak nyata dengan P4.

\section{Penerimaan Keseluruhan}

Berdasarkan sidik ragam diperoleh hasil bahwa perlakuan perbandingan semolina dan tepung beras hitam berpengaruh nyata $(\mathrm{P}<0,05)$ terhadap penerimaan keseluruhan pasta fettucine basah. Berdasarkan Tabel 4, menunjukkan bahwa nilai rata-rata (uji hedonik) terhadap penerimaan keseluruhan pasta fettucine basah berkisar antara 3,70 4,70 dengan kriteria biasa hingga agak suka. Penerimaan keseluruhan pasta fettucine basah tertinggi diperoleh pada perlakuan P3 (agak suka) dan berbeda tidak nyata dengan $\mathrm{P} 2$ dan P0, sedangkan terendah diperoleh pada perlakuan P5 (biasa) dan berbeda tidak nyata dengan P1 dan P4. Penerimaan keseluruhan pasta fettucine basah dipengaruhi oleh beberapa faktor seperti warna, aroma, tekstur dan rasa.

\section{SIMPULAN DAN SARAN}

\section{Simpulan}

1. Perbandingan semolina dan tepung beras hitam berpengaruh terhadap kadar air, kadar abu, total antosianin, kapasitas antioksidan, tekstur dan warna (uji skoring), 
aroma, tekstur dan penerimaan keseluruhan (uji hedonik) pasta fettucine basah.

2.Perbandingan $50 \%$ semolina dan 50\% tepung beras hitam menghasilkan pasta fettucine basah terbaik dengan karakteristik kadar air sebesar 56,49\%, kadar abu sebesar $0,69 \%$, total antosianin sebesar 2,26 $\mathrm{mg} / 100 \mathrm{~g}$, kapasitas antioksidan sebesar 23,02\%, warna hitam keunguan dan biasa, tekstur agak kenyal dan agak suka, aroma agak suka, rasa agak suka, dan penerimaan keseluruhan biasa.

\section{Saran}

Membuat pasta fettucine basah sebaiknya menggunakan perbandingan $50 \%$ semolina : $50 \%$ beras hitam

\section{DAFTAR PUSTAKA}

\section{Anonimus. 2006. Keamanan Pangan. Universitas Pendidikan Indonesia, Bandung.}

Gisslen, W. 2011. Professional Cooking. Seventh Edition. John. Wiley \& Sons, Canada.

Gisslen, W. 2013.Professional Baking.John Wiley \& Sons. Inc, Canada.

Gomez, K. A. dan A. A. Gomez. 1995. Prosedur Statistik Untuk Penelitian Pertanian. UI Press, Jakarta

Lee, J. 2005. Determination of Total Monomeric Anthocyanin Pigment Content of Fruit Juice, Beverages, Natural Colorants, and Wines by the $\mathrm{pH}$ Differential Method: Collaboration Study. Journal of AOAC International, 88 (5): 1269

Mangiri, J., N. Mayulu., dan Kawengian. 2015. Gambaran Kandugan Zat Gizi Pada Beras Hitam (Oryza sativa L.) Kultivar Pare Ambo Sulawesi Selatan. Fakultas Kedokteran Universitas Sam
Ratulangi, Manado.

Narwidina, P. 2009. Pengembangan Minuman Isotonik Antosianin Beras Hitam (Oryza sativa L.indica) dan Efeknya Terhadap Kebugaran dan Aktivitas Antioksidan pada Manusia Pasca Stres Fisik: A Case Control Study. Tidak Dipublikasi. Program Pascasarjana Fakultas Teknologi Pertanian. Universitas Gadjah Mada.

Putri, U dan Y.N. Novita 2013. Uji Kesukaan Pasta Fettucine Subsitusi Tepung CumiCumi. Fakultas Teknologi Pertanian. Universitas Negri Malang.

Soekarto, S. T. 1985. Penilaian Organoleptik untuk Industri Pangan dan Hasil Pertanian. Bhratara Karya Aksara, Jakarta.

Suardi, D. dan I. Ridwan. 2009. Beras hitam, pangan berkhasiat yang belum populer. Warta Penelitian dan Pengembangan Pertanian 31(2): 9 - 10.

Sudarmadji, S. B. Haryono dan Suhardi. 1997. Prosedur Analisa untuk Bahan Makanan dan Pertanian. Liberty, Yogyakarta.

Yun, L. 2001. Free radical scavenging properties of conjugated linoic acids. J. Agric. Food Chem. 49:3452-3456. 